\title{
ENSAIO DE PERMEABILIDADE E ANÁLISE FÍSICA DO SOLO DE VOÇOROCA LOCALIZADA NO DISTRITO DE AMADEU AMARAL, MARÍLIA-SP
}

\section{PERMEABILITY TEST AND PHYSICAL ANALYSIS OF SOIL OF GULLY LOCATED IN THE DISTRICT OF AMADEU AMARAL, MARÍLIA-SP}

\author{
Aline Akemi Mourão Nakata, João Osvaldo Rodrigues Nunes, Carolina \\ Julian.
}

Universidade Estadual Paulista, Faculdade de Ciências e Tecnologias, Engenharia Ambiental, Presidente Prudente, SP. Agência de fomento: Conselho Nacional de Desenvolvimento Científico e Tecnológico (CNPq) e Fundação de Amparo à Pesquisa do Estado de São Paulo (FAPESP). E-mail:

aakemimn@gmail.com.

RESUMO - A erosão é um processo natural que age sobre os solos e as rochas para modificação do relevo da terra e o tipo de solo da área é um fator que influencia sua ocorrência e intensidade. A erodibilidade é um índice que explicita a vulnerabilidade do solo em sofrer um processo erosivo, relacionando as características físico-químicas do solo e/ou o estado de cobertura da terra. $O$ trabalho foi realizado em uma propriedade rural, localizada no Distrito de Amadeu Amaral, no município de Marília/SP e visou a análise física do tipo de solo, sua caracterização e a constatação do coeficiente de permeabilidade do solo, a fim de compreender a relação entre o processo erosivo recorrente e as características do solo. Para isso, foram realizadas análises morfológicas, texturais e do fracionamento utilizando os métodos da EMBRAPA (1997) e um ensaio de permeabilidade. Com a realização do trabalho, percebeu-se que as características do solo atribuem a ele grande susceptibilidade a processos erosivos, o que contribuiu, juntamente com as influências antrópicas, para a aceleração da erosão na área.

Palavras-chave: erosão; análise física de solo; tipo de solo; permeabilidade; oeste paulista.

ABSTRACT - The erosion processes are natural phenomena that acts on soils and rocks to modify the land's relief and the soil type of the area is a factor that influences its occurrence and intensity. The erodibility is an index that explains the vulnerability of the soil to undergo an erosive process, relating the physical-chemical characteristics of the soil and / or the state of land cover. The work took place in a rural property, located in the District of Amadeu Amaral, in the city of Marília / SP and aimed at the physical analysis of the soil type, its classification and the soil permeability coefficient, in order to understand the relation between the recurrent erosive process and the soil characteristics. For this, morphological, textural and fractionation analyzes were performed using the methods of EMBRAPA (1997) and a soil permeability test. With the accomplishment of the work, it was perceived that the soil characteristics attribute to it great susceptibility to erosive processes, which

Recebido em: 09/08/2017 Revisado em: 13/09/2017 Aprovado em: 29/09/2017 contributed, along with the anthropic influences, to the acceleration of the erosion in the area.

Keywords: erosion; physical soil analysis; type of soil; permeability; west of São Paulo. 


\section{INTRODUÇÃO}

Os processos erosivos são fenômenos naturais que fazem parte da dinâmica terrestre. Ao longo do tempo histórico, conforme as práticas agrícolas sem manejo e conservação adequados, associado ao crescimento das áreas urbanas sem planejamento ambiental, a intensidade das chuvas tem impactado os solos sem proteção, provocando vários tipos de erosões.

Neste aspecto, as grandes transformações econômicas e geográficas que ocorreram no Estado de São Paulo, nas últimas décadas, provocaram mudanças ambientais significativas no seu território $A$ infraestrutura e o baixo custo das terras do Centro-Oeste Paulista favoreceram o desenvolvimento mais expressivo dessas atividades no território, o que contribuiu para o agravamento e aceleração de seus processos erosivos (NETO, 1995).

Conforme Bertoni e Lombardi Neto (1999), o manejo inadequado dos solos tem causado redução da capacidade de infiltração de água no solo, aumento do escoamento superficial, perda de solos e, consequentemente, processos erosivos agravantes. A área de estudo em questão localiza-se no Distrito de Amadeu Amaral, no município de Marília- SP, na qual possui processos erosivos lineares e laminares extremamente acelerados, principalmente os sulcos, ravinas e voçoroca, em que ao atingir o aquífero freático, ocasionou o afloramento de nascentes.

$\mathrm{Na}$ região do Planalto Residual de Marília predominam os Argissolos Vermelhos e Neossolos Litólicos (OLIVEIRA et al., 1999). Os Argissolos Vermelhos caracterizam-se por ser de cor avermelhada, com textura arenosa e relacionado com solos originários de rochas sedimentares da Formação Marília. Apresenta menor relação textural entre os horizontes $\mathrm{A}$ ou $\mathrm{E}$ e o $\mathrm{B}$ textural (OLIVEIRA et al, 1999; EMBRAPA, 2006). Possui grande erodibilidade decorrente da mudança textural entre os horizontes $A+E$, de textura arenosa, com o horizonte $\mathrm{Bt}$, de textura argilosa. Este tipo de solo, associado à história de ocupação, apresenta vulnerabilidade muito alta à erosão (CRUZ, 2001; LEPSCH, 2010).

O objetivo desse estudo foi analisar e caracterizar aspectos do solo uma voçoroca localizada em propriedade rural do Distrito de Amadeu Amaral, a fim de compreender a relação existente entre as características do solo e os processos erosivos expressivos.

\section{METODOLOGIA}

Inicialmente, realizou-se uma visita na área, na qual foram coletadas amostras de solo. Para caracterização detalhada da área de estudo, foi realizada a abertura de uma trincheira no setor a montante dos focos 
erosivos, com coordenadas aproximadas zona 22 K latitude 7528960 m e longitude 596939 m, visando identificar o perfil de solo e seus respectivos horizontes pedológicos. Além disto, foi realizado o ensaio de permeabilidade de solo.

- $\quad$ Análises granulométricas e do fracionamento da areia

As amostras foram levadas a laboratório para realizar análises morfológicas, texturais e do fracionamento utilizando os métodos da EMBRAPA (1997). Inicialmente as amostras foram separadas e colocadas para secagem ao ar livre por uma semana. Posteriormente, elas foram destorroadas, utilizando um pistilho, almofariz e da peneira com abertura de $2,00 \mathrm{~mm}$.

Em seguida, em triplicata, foram pesados $10 \mathrm{~g}$ de cada amostra utilizando um Erlenmeyer. Depois foram adicionados $20 \mathrm{~mL}$ de água deionizada, com o auxílio de uma proveta de $25 \mathrm{~mL}$, e, com a pipeta volumétrica, $10 \mathrm{~mL}$ de solução de hidróxido de sódio ( $\mathrm{NaOH})$. Então, os Erlenmeyers foram dispostos na mesa vibratória por um período de 6 horas, objetivando a desagregação dos diferentes grãos que constituem o solo.

Após o período de agitação filtrou-se a solução de solo com o auxílio de uma peneira de abertura de $0,053 \mathrm{~mm}$. Para isso a peneira foi encaixada em um funil e ambos foram colocados sobre uma proveta de $1000 \mathrm{~mL}$. A solução foi então despejada sob a peneira e lavada com água deionizada até completar o volume da proveta.

As frações retidas na peneira foram depositadas nas Placas de Petri (anteriormente pesadas após um período na estufa) e levadas para a estufa por um período de 24 horas a uma temperatura de $105^{\circ} \mathrm{C}$. Transcorrido este período, as placas foram dispostas no dessecador para esfriar e posteriormente pesadas.

Posteriormente, as provetas contendo argila e silte resultante da filtragem das amostras, são colocadas no tanque, e, após medir a temperatura das soluções com um termômetro, determina-se o tempo de pipetagem, ou seja, o espaço de tempo entre a agitação de uma proveta e sua pipetagem, conforme a Tabela 1, sendo que a agitação é realizada com o auxílio de um bastão específico e cada proveta foi agitada por 30 segundos, com um intervalo de tempo de 1 minuto entre elas. 
Tabela 1. Tempo de sedimentação para a pipetagem.

\begin{tabular}{|c|c|}
\hline Temperatura ( $\mathrm{O}$ C) & Tempo (h e') \\
\hline 15 & $4 \mathrm{~h}$ e $19^{\prime}$ \\
\hline 16 & $4 \mathrm{~h}$ e $12^{\prime}$ \\
\hline 17 & $4 \mathrm{~h}$ e $05^{\prime}$ \\
\hline 18 & $3 h$ e $59^{\prime}$ \\
\hline 19 & $3 h$ e 53' \\
\hline 20 & $3 h$ e $48^{\prime}$ \\
\hline 21 & $3 h$ e $42^{\prime}$ \\
\hline 22 & $3 h$ e $37^{\prime}$ \\
\hline 23 & $3 h$ e $32^{\prime}$ \\
\hline 24 & $3 h$ e $27^{\prime}$ \\
\hline 25 & $3 h$ e $22^{\prime}$ \\
\hline 26 & $3 \mathrm{~h}$ e $18^{\prime}$ \\
\hline 27 & $3 h$ e $13^{\prime}$ \\
\hline 28 & $3 h$ e 09' \\
\hline 29 & $3 h$ e $05^{\prime}$ \\
\hline 30 & $3 h$ e $01^{\prime}$ \\
\hline
\end{tabular}

Fonte: EMBRAPA (1997).

Após o intervalo de tempo entre a agitação das provetas e a pipetagem, iniciouse o procedimento com a pipetagem de $5 \mathrm{~mL}$ de solução, contendo argila, a $5 \mathrm{~cm}$ de profundidade. O conteúdo é transferido para um béquer de $40 \mathrm{~mL}$ (anteriormente pesados após um período na estufa), adicionando $5 \mathrm{~mL}$ de água deionizada.

Por fim, os béqueres foram levados a estufa durante um período de 24 horas a uma temperatura de $105^{\circ} \mathrm{C}$. Posteriormente, os mesmos foram dispostos no dessecador $\mathrm{e}$ pesados.

Ao final, foram realizados os cálculos de porcentagem de areia, silte e argila, conforme as equações abaixo.

Porcentagem de areia:

M_areia=P2 (peso da placa com areia)-P1 (peso da placa)

$\%$ areia $=10 * \mathrm{M} \_$areia

Porcentagem de argila:

M_argila=P4 (peso do bequer com a argila)P3 (peso do béquer)

$\%$ argila $=($ M_argila- 0,002$) * 2000$

Porcentagem de silte:

$\%$ silte $=100 \%-\%$ areia- $\%$ argila

A partir da determinação das frações de areia, argila e silte utilizou-se do Diagrama de Classes Texturais (Figura 1) para se determinar a qual classe pertencia. 
Figura 1. Diagrama textural proposto pelo U.S.D.A.

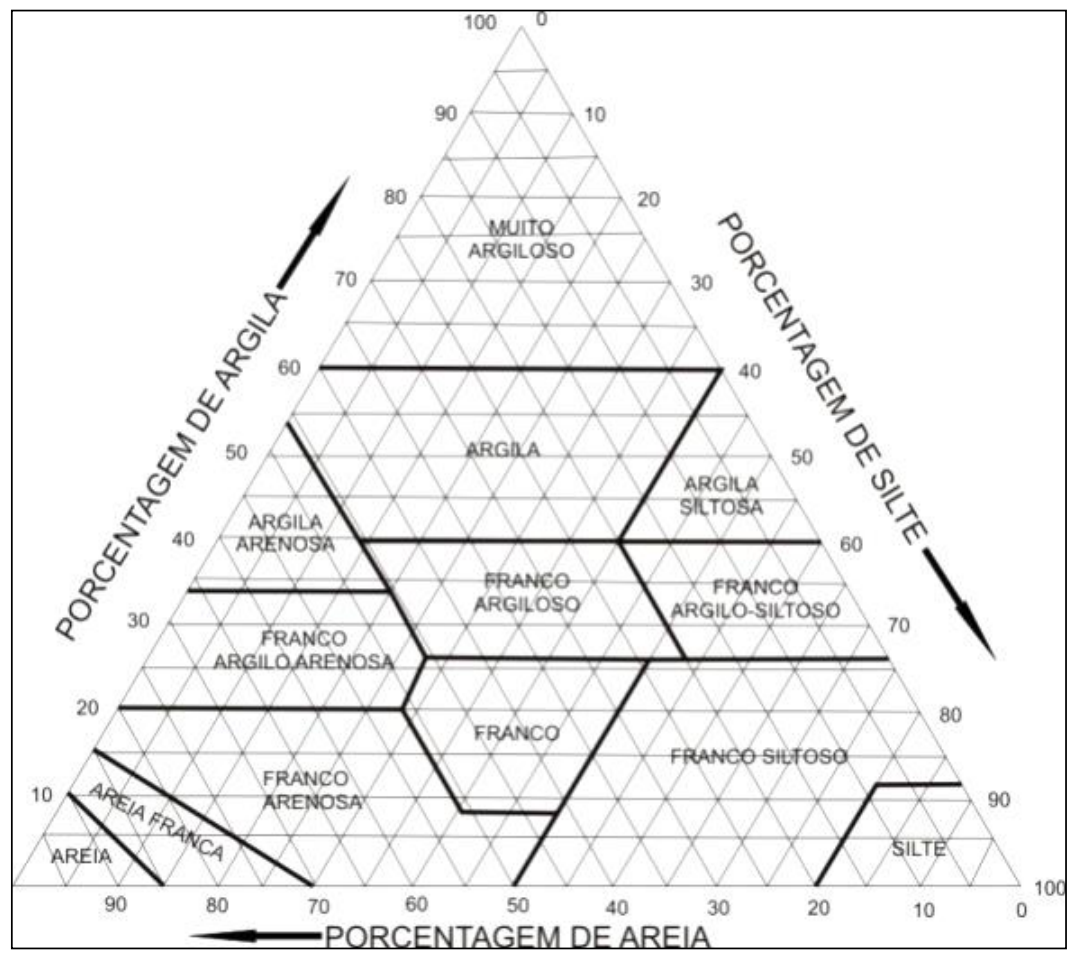

Fonte: USDA (1951) apud Lemos e Santos (1996)

Com a areia presente nas placas de Petri realizou-se o fracionamento das mesmas. Para isso, as amostras foram levadas à peneiradora, ajustada para tempo de 5 minutos e frequência de 1500 vibrações por minuto, sendo que o jogo de peneiras corresponde as seguintes aberturas: 2,00; 1,$00 ; 0,50 ; 0,250 ; 0,125 ; 0,062 \mathrm{~mm}$, correspondendo as granulometrias de muito grossa, grossa, média, fina e muito fina, respectivamente. Com o auxílio de um pincel a areia de cada uma das peneiras foi transferida para um béquer e posteriormente pesado, uma por vez. Por relação de entre as massas foi então obtido também as percentagens de cada fração.

\section{Caracterização pedológica}

Baseando-se nos procedimentos em Lemos e Santos (1996); Kiehl (1979); IBGE (2007). Neste estudo morfológico foi considerado:

- Cor: de acordo com a Carta de Munsell (2000).

- Espessura e arranjo dos horizontes;

- Transição entre os horizontes: Abrupta $<2,5 \mathrm{~cm}$; Clara $2,5-7,5 \mathrm{~cm}$; Gradual 7,5-12,5cm; Difusa $>12,5 \mathrm{~cm}$ (IBGE, 2007).

- Textura (proporção relativa das frações granulométricas que compõem o solo) considerando a classe de textura exposta em Lemos e Santos (1996).

- Plasticidade: não plástica, ligeiramente plástica, plástica, muito plástica. 
A plasticidade está relacionada com o grau de resistência à deformação (IBGE, 2007);

- Estrutura: blocos angulares e subangulares, blocos granulares e em grumos;

- Porosidade: volume de solo ocupado pela água e pelo ar podendo ser: pouco porosos, poros comuns e muito porosos.

- Cerosidade: aspecto brilhante e ceroso na superfície podendo ser, no que se refere ao grau de desenvolvimento: fraca, moderada, forte e, com relação à quantidade: pouco, comum ou abundante;

- Consistência: solo seco, considerando a dureza (solta, macia, ligeiramente dura, dura, muito dura, extremamente dura) e solo úmido, considerando a friabilidade (solta, muito friável, friável, firme, muito firme, extremamente dura).

Densidade: aumenta em profundidade graças ao adensamento resultante da pressão das camadas superiores e da eluviação de argila que se relaciona com a diminuição da porosidade;

- Tipo de solo: Latossolo, Argissolo, Litossolo ou Neossolo, Hidromórfico ou Gleissolo etc.

\section{Permeabilidade do solo}

Com relação ao ensaio de permeabilidade, ele foi realizado utilizando o Permeâmetro de Guelph.
Foi realizada a montagem do permeâmetro segundo o seu manual de instruções, e feito um furo no solo, utilizando o trado de $60 \mathrm{~cm}$ de profundidade. Assim, inseriu-se água no permeâmetro para dar início aos procedimentos.

O Permeâmetro de Guelph pode ser ajustado para solos argilosos ou arenosos através da combinação de seus reservatórios. Solos argilosos por serem menos permeáveis ocorre uma menor taxa de infiltração, sendo utilizado apenas o reservatório interno. Solos arenosos são mais permeáveis, apresentando uma taxa de infiltração maior, sendo utilizados os reservatórios interligados.

As leituras foram realizadas em tempos regulares, em intervalos de 2 (dois) minutos. A diferença das leituras em intervalos consecutivos, em centímetros, dividida pelo intervalo de tempo, em segundos, resultou no valor da taxa de queda $d^{\prime}$ água $(R)$ no reservatório $(\mathrm{cm} / \mathrm{s})$.

O procedimento foi executado utilizando duas alturas a partir da elevação do tubo de ar até a diferença de leituras em três intervalos consecutivos seja constante. Para a primeira taxa denominou-se R1, que representava a taxa de queda em estado estável da água no reservatório em $\mathrm{H} 1$, em que $\mathrm{H} 1$ representa a altura de $5 \mathrm{~cm}$ no tubo de ar, ou seja, a primeira altura estabelecida. Para a segunda taxa denominou-se R2, que foi definida como taxa de queda em estado 
estável da água no reservatório em $\mathrm{H} 2$, em que $\mathrm{H} 2$ representa a altura de $10 \mathrm{~cm}$ no tubo de ar.

Após este procedimento, calculou-se a condutividade hidráulica saturada de campo (Kfs). No caso do emprego da combinação de reservatórios a equação a ser emprega é:

$K_{-} f s=(0,0041) \cdot(X) \cdot(R 2)-(0,0054) \cdot(X) \cdot(R 1)$

Em que $X=35,39 \mathrm{~cm} 2$, que representa a constante utilizada quando os reservatórios forem interligados $(\mathrm{cm} 2)$.

No caso de apenas o reservatório interno ser selecionado o cálculo de $\mathrm{Kfs}$ deve ser realizado por meio da seguinte equação:
K_fs $=(0,0041) \cdot(X) \cdot(R 2)-(0,0054) \cdot(X) \cdot(R 1)$

Em que $Y=2,19 \mathrm{~cm} 2$, que representa a constante utilizada quando apenas o reservatório interno estiver selecionado $(\mathrm{cm} 2)$.

Sendo que, ambas as constantes estão identificadas na válvula do reservatório do permeâmetro.

A Tabela 2 apresenta valores típicos do coeficiente de permeabilidade (médios) em função dos materiais (solos arenosos e argilosos).

Tabela 2. Valores típicos do coeficiente de permeabilidade.

\begin{tabular}{c|c|c|c}
\multicolumn{2}{c|}{ PERMEABILIDADE } & TIPO DE SOLO & $\boldsymbol{K}(\mathrm{cm} / \mathrm{s})$ \\
\hline \multirow{2}{*}{ SOLOS PERMEÁVEIS } & Alta & Pedregulhos & $>10^{-3}$ \\
\cline { 2 - 4 } & Alta & Areias & $10^{-3}$ a $10^{-5}$ \\
\cline { 2 - 4 } & Baixa & Siltes e Argilas & $10^{-5}$ a $10^{-7}$ \\
\hline \multirow{2}{*}{ SOLOS IMPERMEÁVEIS } & Muito baixa & Argila & $10^{-7}$ a $10^{-9}$ \\
\cline { 2 - 4 } & Baixíssima & Argila & $<10^{-9}$
\end{tabular}
Fonte: CRUZ (1996).

\section{RESULTADOS}

- $\quad$ Análises granulométricas e do fracionamento da areia

A partir da verificação da situação que a área se encontrava foram escolhidos 10 pontos onde foram montadas as estruturas de contenção a erosão linear (Figura 2), representando os sedimentos carreados por se tratarem de cavas de escoamento, obtendo suas coordenadas e amostras de solo (Figura 3) para realização de análises texturais. 
Figura 2. Posicionamento dos pontos de coleta das amostras com os pontos de erosão.

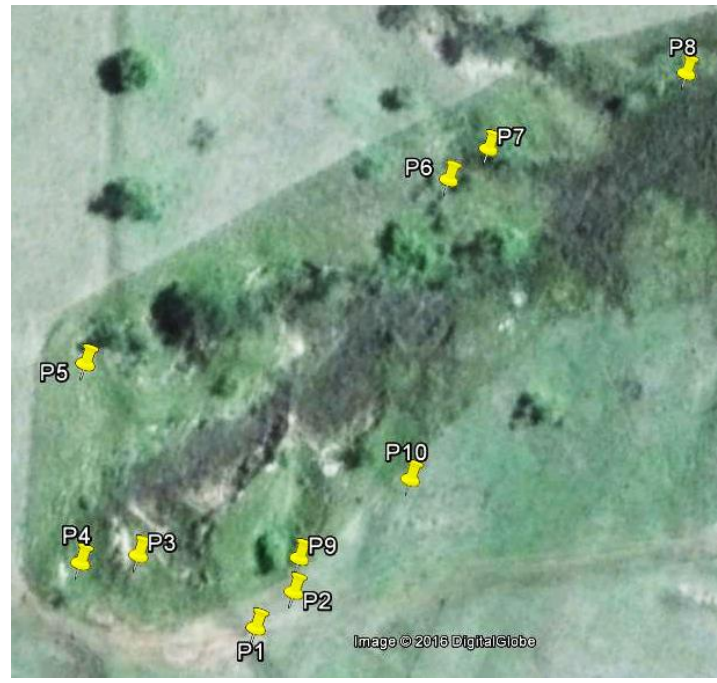

Fonte: Google Earth ${ }^{\mathrm{T}}$, 2015.

Com as amostras coletadas, foram realizadas as análises granulométricas das amostras no Laboratório de Sedimentologia e
Figura 3. Imagem da coleta de amostragem em um dos pontos.

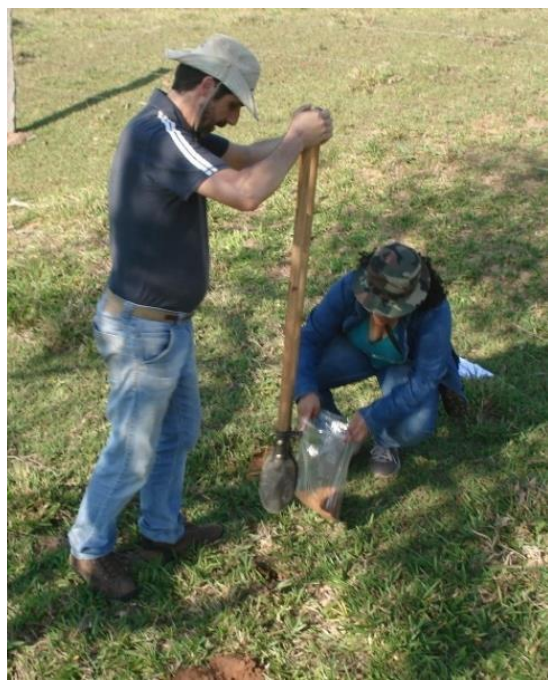

Fonte: Autora, 2015

Análise de Solos, e os resultados finais obtidos foram dispostos na Tabela 3.

Tabela 3. Análise granulométrica das amostras de solo dos pontos iniciais para montagem dos barramentos.

\begin{tabular}{ccccccc}
\hline \multirow{2}{*}{ Ponto } & \multicolumn{2}{c}{ Localização do ponto (UTM - zona 22K) } & Argila & Areia & Silte & \multirow{2}{*}{ Classe textural } \\
\cline { 2 - 6 } & Latitude (m S) & Longitude (m $\mathbf{~})$ & $\mathbf{g} / \mathbf{k g}^{-1}$ & $\mathbf{g} / \mathbf{k g}^{-1}$ & $\mathbf{g} / \mathbf{k g}^{-1}$ & \\
\hline $\mathbf{1}$ & 7528952 & 597000 & 84,7 & 874,8 & 40,5 & Areia Franca \\
$\mathbf{2}$ & 7528966 & 597003 & 60,7 & 923,7 & 15,6 & Areia \\
$\mathbf{3}$ & 7528955 & 596969 & 99,3 & 888,6 & 12,1 & Areia Franca \\
$\mathbf{4}$ & 7528947 & 596959 & 80,0 & 914,0 & 6,0 & Areia \\
$\mathbf{5}$ & 7528985 & 596936 & 73,0 & 922,6 & 4,4 & Areia \\
$\mathbf{6}$ & 7529064 & 596983 & 46,0 & 942,7 & 11,3 & Areia \\
$\mathbf{7}$ & 7529075 & 596987 & 43,0 & 931,3 & 25,7 & Areia \\
$\mathbf{8}$ & 7529115 & 597017 & 47,3 & 941,0 & 11,6 & Areia \\
$\mathbf{9}$ & 7528973 & 597000 & 47,0 & 930,1 & 22,9 & Areia \\
$\mathbf{1 0}$ & 7529001 & 597012 & 66,0 & 901,7 & 32,3 & Areia \\
\hline
\end{tabular}

Fonte: Autora, 2015

Quase todas as amostras, segundo o diagrama das classes texturais, foram classificadas como Areia e duas Areia Franca. Quanto ao fracionamento da areia (Tabela 4) os maiores percentuais foram de areias médias e finas, e um menor, mas significativo, muito fina. 
Tabela 4. Fracionamento das amostras dos pontos iniciais de montagem de barramentos.

\begin{tabular}{cccccc}
\hline Ponto & Muito grossa (\%) & Grossa (\%) & Média (\%) & Fina (\%) & Muito Fina (\%) \\
\hline $\mathbf{1}$ & 0,0 & 4,5 & 44,5 & 36,6 & 13,3 \\
$\mathbf{2}$ & 0,1 & 5,7 & 44,5 & 38,4 & 11,2 \\
$\mathbf{3}$ & 0,0 & 7,5 & 47,5 & 34,1 & 10,9 \\
$\mathbf{4}$ & 0,1 & 11,0 & 56,8 & 25,4 & 6,6 \\
$\mathbf{5}$ & 0,1 & 8,3 & 50,0 & 31,1 & 10,5 \\
$\mathbf{6}$ & 0,0 & 6,7 & 49,7 & 32,7 & 10,4 \\
$\mathbf{7}$ & 0,1 & 5,9 & 44,9 & 36,2 & 12,7 \\
$\mathbf{8}$ & 0,1 & 5,5 & 42,5 & 37,5 & 13,6 \\
$\mathbf{9}$ & 0,1 & 5,5 & 44,2 & 37,9 & 11,8 \\
$\mathbf{1 0}$ & 0,0 & 3,1 & 35,3 & 42,0 & 18,4 \\
\hline
\end{tabular}

Fonte: Autora, 2015.

- $\quad$ Caracterização pedológica

A partir das análises realizadas,
A, C1, C2 e C3, conforme ilustrado na Figura

4.

identificou-se a existência de três horizontes:

Figura 4. Descrição geral do perfil de solo.

\begin{tabular}{|c|c|c|c|c|c|c|}
\hline \multicolumn{7}{|c|}{ Neossolo Quartzarênico } \\
\hline \multicolumn{3}{|l|}{$\begin{array}{l}\text { Data } \\
\text { Identificação }\end{array}$} & \multicolumn{3}{|l|}{$\begin{array}{l}25 \text { de junho de } 2016 \\
\text { Neossolo Quartzarênico }\end{array}$} & \\
\hline \multirow{2}{*}{\multicolumn{3}{|c|}{$\begin{array}{l}\text { Localização } \\
\text { Situacão e Declive }\end{array}$}} & \multicolumn{3}{|c|}{ Distrito de Amadeu Amaral, Marilia/SP } & \\
\hline & & & Vertente de longo com & nprimento de rampa de 1 & 10 a $15 \%$ & \\
\hline \multicolumn{3}{|l|}{ Coordenadas } & \multicolumn{3}{|c|}{$22^{\circ} 20^{\prime} 33^{\prime \prime}$ S e $50^{\circ} 03^{\prime} 31^{\prime \prime}$ W } & \\
\hline \multicolumn{3}{|c|}{ Cobertura Vegetal Primária e Atual } & \multicolumn{3}{|c|}{ Floresta Estacional e gramíneas } & \\
\hline \multicolumn{3}{|c|}{ Altitude } & \multicolumn{3}{|l|}{$461 \mathrm{~m}$} & \\
\hline & \multicolumn{3}{|c|}{ Arenito da Formação Marilia (Grupo Bauru) } & \\
\hline \multicolumn{3}{|c|}{ Cronologia } & \multicolumn{3}{|c|}{ Cenozóico Superior } & \\
\hline \multicolumn{3}{|l|}{ Relevo Local } & \multicolumn{3}{|c|}{ Colinozo suavemente ondulado } & \\
\hline \multicolumn{3}{|l|}{ Erosão } & \multicolumn{3}{|l|}{ Voçoroca } & \\
\hline \multicolumn{3}{|l|}{ Drenagem } & \multicolumn{3}{|l|}{ Bem drenado } & \\
\hline \multicolumn{3}{|l|}{ Uso Atual } & \multicolumn{3}{|c|}{ Pastagem (montante) e APP (jusante) } & \\
\hline \multicolumn{3}{|c|}{ Descrito e Coletodo por } & \multicolumn{3}{|c|}{$\begin{array}{l}\text { João Osvaldo Rodrigues Nunes, Aline Akemi Mourão Nakata e } \\
\text { Carolina Julian }\end{array}$} & \\
\hline \multirow{2}{*}{\multicolumn{3}{|c|}{$\begin{array}{l}\text { Horizontes } \\
\text { Profundidade (cm) }\end{array}$}} & A & C1 & C2 & C3 \\
\hline & & & $0-35$ & $35-110$ & $110-127$ & $127-150+$ \\
\hline \multicolumn{3}{|c|}{ Características morfológicas } & $\begin{array}{l}\text { Marrom (10YR 3/3), } \\
\text { transição abrupta, não } \\
\text { plástica, blocos gra- } \\
\text { nulares e em grumos, } \\
\text { muito poroso, consis- } \\
\text { tência em solo seco: } \\
\text { solta eem solo úmido: } \\
\text { friável }\end{array}$ & $\begin{array}{l}\text { Cinza (10YR 6/3), tran- } \\
\text { sição gradual, não } \\
\text { plástica, blocos } \\
\text { semi-angulares,muito } \\
\text { poroso, consistência } \\
\text { em solo seco: solta e } \\
\text { em solo úmido: friável }\end{array}$ & $\begin{array}{l}\text { Cinza (10YR 5/3), tran- } \\
\text { sição gradual, não plás- } \\
\text { tica, blocos semi-angu- } \\
\text { lares, muito poroso, } \\
\text { consistência em solo } \\
\text { seco: solta e em solo } \\
\text { úmido: friável }\end{array}$ & $\begin{array}{l}\text { Cinza (10YR 5/3), tran- } \\
\text { siçăo gradual, não } \\
\text { plástica, blocos } \\
\text { semi-angulares, muito } \\
\text { poroso, consistência } \\
\text { em solo seco: solta e } \\
\text { em solo úmido: friável }\end{array}$ \\
\hline \multirow{4}{*}{ Análise textural } & Areia & \multirow{3}{*}{$\mathbf{g} \cdot \mathrm{Kg}^{-1}$} & 906,2 & 942,7 & 889,9 & 773,1 \\
\hline & Silte & & 87,2 & 57,3 & 97,5 & 88,2 \\
\hline & Argila & & 6,6 & 0 & 12,6 & 138,7 \\
\hline & \multicolumn{2}{|c|}{ Classe textural } & Areia & Areia & Areia & Areia Franca \\
\hline Densidade & \multicolumn{2}{|c|}{ g.cm $\mathrm{cm}^{-3}$} & 1,81 & 1,61 & 1,75 & 1,90 \\
\hline
\end{tabular}

Fonte: Autora, 2016. 
O horizonte A possui cor 10YR 3/3, espessura de $35 \mathrm{~cm}$, com transição abrupta para o horizonte $C$, não possui plasticidade e cerosidade, sua estrutura é em grumos, textura arenosa, com muitos poros e possui consistência solta tanto com solo seco como úmido, apresentando densidade $1,81 \mathrm{~g} / \mathrm{cm}^{3}$.

O horizonte C1 possui cor 10YR 6/3, espessura de $75 \mathrm{~cm}$, com uma transição gradual para o horizonte $\mathrm{C} 2$, não possui plasticidade e cerosidade, sua estrutura é de blocos semianulares, textura arenosa, com muitos poros e possui consistência solta tanto com solo seco como úmido, apresentando densidade $1,61 \mathrm{~g} / \mathrm{cm}^{3}$.

O horizonte C2 possui cor 10YR 5/4, espessura de $17 \mathrm{~cm}$, com transição gradual, sua estrutura é de blocos semianulares, não possui plasticidade e cerosidade, textura arenosa, com muitos poros e possui consistência solta tanto com solo seco como úmido, apresentando densidade $1,75 \mathrm{~g} / \mathrm{cm}^{3}$.

O horizonte C3 possui cor 7,5YR 6/3, espessura de $23 \mathrm{~cm}$, com transição gradual, sua estrutura é de blocos semianulares, não possui plasticidade e cerosidade, textura arenosa, com muitos poros e possui consistência solta com solo seco e macia quando úmido, apresentando densidade 1,90 $\mathrm{g} / \mathrm{cm}^{3}$.

Assim, o solo possui textura arenosa, muitos poros, estrutura grumosa $(A)$ e com blocos semianulares (C1, C2 e C3), não possui plasticidade ou cerosidade e consistência solta ao longo de todo o perfil. A partir de todas as características morfológicas, associado aos dados de textura com mais de 800 g.kg-1 da fração areia, identificou-se como sendo um Neossolo Quartzarênico.

- $\quad$ Permeabilidade do solo

Como resultado obteve-se um valor para a condutividade hidráulica saturada em campo de aproximadamente $1,21 \cdot 10-2 \mathrm{~cm} / \mathrm{s}$ sendo classificado, segundo a Tabela 2, como sendo um solo permeável de alta permeabilidade.

\section{DISCUSSÃO}

- $\quad$ Análises granulométricas e do fracionamento da areia

Com todos os resultados das análises percebeu-se que o material em geral é de natureza pouco coesa, muito friável e de fácil transporte. Sendo assim, as características físicas do solo da área de estudo influenciam o agravamento de erosões, pois não são recomendados para o tipo de atividade realizada na propriedade que é a criação de gado.

- $\quad$ Caracterização pedológica Segundo o Sistema Brasileiro de Classificação de Solos da EMBRAPA (2006) os Neossolos são solos pouco evoluídos, que não possuem horizonte $B$ diagnóstico 
definido, e são solos em formação, seja pela reduzida atuação dos processos pedogenéticos ou por características do material originário.

De maneira mais específica, a EMBRAPA (2006) caracteriza os Neossolos Quartzarênico como de sequência de horizontes $A-C$, mas que possui textura areia ou areia franca em todos os horizontes. Tais solos são essencialmente quartzosos, ou seja, apresentam nas frações areia grossa e areia fina $95 \%$ ou mais de quartzo, calcedônia e opala e, praticamente, ausência de minerais primários alteráveis. Sendo assim, esses solos são menos resistentes ao intemperismo, possuem teores de matéria orgânica, fósforo e micronutrientes muito baixos, apresentando lixiviação de nitrato intensa devido à textura essencialmente arenosa.

\section{- $\quad$ Permeabilidade do solo}

Permeabilidade é a propriedade, que o solo apresenta, de permitir o escoamento da água Granulometria, índice de vazios, composição mineralógica, estrutura, fluído, macroestrutura e a temperatura são os principais fatores que influenciam no coeficiente de permeabilidade (VARGAS, 2017).

A alta permeabilidade apresentada indica a facilidade que a água tem de transpassar o solo. Uma vez que a área é de pastagem, possuindo pouca cobertura vegetal, a passagem da água retira os nutrientes do solo, degradando seus horizontes, e contribuindo para o agravamento dos processos erosivos.

\section{CONCLUSÃO}

A partir de todos os dados obtidos, percebe-se que a grande quantidade de fração areia nas amostras constata o solo arenoso que a área de estudo apresenta. Isso foi reafirmado a partir da caracterização pedológica, que resultou em Neossolo Quartzarênico, pois esse tipo de solo apresenta uma grande susceptibilidade ao avanço de processos erosivos, devido à sua constituição de seus horizontes.

Tais processos erosivos são agravados devido à atividade de pecuária realizada na propriedade. Com a presença do gado, a cobertura vegetal se torna escassa, além da capacidade de retenção de água ser diminuída. Dessa forma, para o solo que apresentou coeficiente de permeabilidade alto, a água somente transpassa pelo solo, sem que possa ser retida em sua maioria, e carreando sedimentos para os corpos hídricos.

A partir disso, compreende-se a situação atual de degradação da área, em as atividades antrópicas, aliadas às características do solo não recomendáveis para tais, acelerem os processos erosivos, 
contribuindo para a deterioração da

propriedade.

\section{REFERÊNCIAS}

BERTONI, J.; LOMBARDI NETO, F. Conservação do solo. 4. ed. São Paulo: Ícone, 1999.

CRUZ, C. Análise comparativa da evolução das voçorocas nos anos de 1962 e 1999 nos municípios de Pompéia e Oriente, SP. 2001. 105 f. Dissertação (Mestrado) - Instituto de Geociências e Ciências Exatas, Universidade Estadual Paulista, 2001.

CRUZ, P. L. 100 Barragens Brasileiras: casos históricos, materiais de construção e projeto. São Paulo: Oficina de Textos, 1996.

EMBRAPA. Centro Nacional de Pesquisa de Solos (Rio de Janeiro, RJ). Sistema brasileiro de classificação de solos. 3. ed. Rio de Janeiro: Embrapa, 2006.

EMBRAPA. Centro Nacional de Pesquisa de Solos. Manual de métodos de análise de solos. 2. ed. Rio de Janeiro, Embrapa, 1997. $212 \mathrm{p}$.

IBGE. Manual Técnico de Pedologia. 2. ed. Rio de Janeiro: IBGE, 2007.

KIEHL, E. J. Manual de edafologia: relações solo-planta. São Paulo: Agronômica Ceres, 1979. 262p.

LEMOS, R. C.; SANTOS, D. S. Manual de descrição e coleta de solo no campo. 3. ed. Campinas: Sociedade Brasileira de Ciências do Solo, 1996.

LEPSCH, I. F. Formação e Conservação dos Solos. 2. ed. São Paulo: Oficina de Textos, 2010. 178p.

NETO, J. L. S. A erosividade das chuvas no Estado de São Paulo. Revista do
Departamento de Geografia da Faculdade de Filosofia, Letras e Ciências Humanas da Universidade de São Paulo, v.9, p.35-49, 1995.

OLIVEIRA, J. B. et al. Solos do Estado de São Paulo: descrição das classes registradas no mapa pedológico. Campinas: Instituto Agronômico, 1999. 112 p.

VARGAS, R. Mecânica dos solos. Disponível em:

$<$ www.ufrrj.br/institutos/it/deng/rosane/.../p ermeabilidade\%20do\%20solo.ppt>. Acesso 07 ago. 2017 